The role of family involvement in fostering an innovation-supportive stewardship culture

Non Peer-reviewed author version

BAMMENS, Yannick; VAN GILS, Anita \& VOORDECKERS, Wim (2010) The role of family involvement in fostering an innovation-supportive stewardship culture. In:

Toombs, L. (Ed.) Academy of Management Best Paper Proceedings., p.1-6.

Handle: http://hdl.handle.net/1942/11754 


\title{
THE ROLE OF FAMILY INVOLVEMENT IN FOSTERING AN INNOVATION-SUPPORTIVE STEWARDSHIP CULTURE
}

\author{
YANNICK BAMMENS \\ School of Business and Economics \\ Maastricht University \\ P.O. Box 616, 6200 MD Maastricht, The Netherlands \\ ANITA VAN GILS \\ Maastricht University, The Netherlands \\ WIM VOORDECKERS \\ Hasselt University, Belgium
}

\section{INTRODUCTION}

The last few decades have seen a substantial increase in scholarly attention devoted to family firms. This interest is more than appropriate given the dominance of family firms as an organizational form, especially among privately-held SMEs, and their significant contribution to economies across the globe (IFERA, 2003). Hitherto, family business scholars have been preoccupied with issues of continuity (e.g., succession and governing boards) more so than with issues of renewal (e.g., entrepreneurship and innovation) (Zahra \& Sharma, 2004). Yet business organizations operate in dynamic and competitive environments that are increasingly characterized by rapid and discontinuous change (Hitt, 2000). In order to safeguard the competitiveness of their firm, business leaders must respond to these changes by investing in innovation and exploiting the opportunities that arise in such changing environments (Sirmon et al., 2007). In view of that, it is important to develop a deeper understanding of the relationship between family involvement and the firm's innovation capacity (Gudmundson et al., 2003). The purpose of this study is to present a theoretical model on the relationship between family involvement and technological innovation (i.e., process and product innovation), and to test derived hypotheses using a sample of privately-held manufacturing SMEs.

We use a stewardship-theoretic lens and insights drawn from the innovation, selfdetermination and family business literatures to develop a theoretical model outlining how and when family involvement facilitates the intra-organizational innovation process. By extracting themes from stewardship theory (Davis et al., 1997) we propose the notion of a stewardship culture consisting of three dimensions: an autonomous orientation, a high-trust orientation, and a collective orientation. These three cultural dimensions will be related to the idea generation phase, the idea dissemination phase, and the idea realization phase, respectively, of the innovation process. Then, based on self-determination theory and the family business literature, we explain how the social conditions prevailing in different generational forms of family firms and their nonfamily counterparts may foster versus thwart this innovation-supportive stewardship culture. This article thus concentrates on the relationships between family involvement, organizational culture, and the entrepreneurial dimension of innovation. In the next section, we develop our theoretical model and derive hypotheses from it. After that, we describe our exploratory empirical study and present its results. 


\section{THEORETICAL BACKGROUND AND HYPOTHESES}

\section{Stewardship Culture and Innovation}

In this section, we develop the notion of a stewardship culture consisting of three dimensions thought to be associated with innovative performance: autonomy, collectivism, and the resultant high-trust climate. We refer to this innovation-supportive organizational culture as a stewardship culture because these three dimensions are derived from the Davis et al. (1997) stewardship-theoretic model. A stewardship culture reflects and endorses the basic belief that organizational members are inclined to integrate themselves into the larger organization (social integration) and to internalize organizational demands into a unified sense of self (psychological integration), and have a propensity toward psychological growth (Davis et al., 1997; Deci \& Ryan, 2000). We now discuss the three cultural dimensions in greater detail and explicate their respective link with the three phases of the innovation process, namely idea generation, idea dissemination and idea realization.

Autonomous Orientation and Idea Generation. The first dimension of a stewardship culture comprises its focus on the autonomous form of motivation. Autonomous motivation involves acting with a sense of volition and can be contrasted with controlled motivation in which individuals feel pressured to perform a certain task (Ryan \& Deci, 2000). More specifically, organizational members who are autonomously motivated to perform an activity do so because they find the activity genuinely interesting (i.e., intrinsic regulation) or important (i.e., well-internalized extrinsic regulation); those who have a controlled motivation do so because of interpersonal controls like rewards or punishments (i.e., external regulation) or intrapersonal controls like avoiding feelings of guilt or shame (i.e., introjected extrinsic regulation). Organizations with a stewardship culture allow for and foster their members' autonomous motivation by means of, for instance, a focus on employee empowerment and the design of interesting jobs with broad and satisfying responsibilities (Davis et al., 1997).

We contend that the prevalence of an autonomous orientation within firms facilitates the generating of innovation ideas, which is the first phase of the innovation process. Generating ideas for new products and processes requires two important ingredients, namely creativity and personal initiative (Rank et al., 2004). Creativity is primarily an intraindividual cognitive process, with numerous scholars emphasizing the importance of autonomous motivation for spurring creativity (e.g., Amabile, 1988; McLean, 2005). Especially the intrinsic form of autonomous motivation has been argued to encourage creativity. Yet creativity alone is not enough, it needs to be complemented with personal initiative (Rank et al., 2004). Both prior and after the initial creation of creative ideas, organizational members must engage in various selfinitiated behaviors that go beyond prescribed job contents such as thinking about opportunities in the changing technological/market environment, engaging in explorative experiments, and spending time and energy fleshing out ideas. To show initiative on the job, organizational members need to have a sense of ownership over their work and experience autonomy in the organizing of the tasks they are given (Baer \& Frese, 2003).

High-Trust Orientation and Idea Dissemination. This second dimension of a stewardship culture, the prevalence of trust among organizational members, is a consequence of the other two stewardship dimensions. That is, the autonomous and the collective orientation (see below) are both situated at deeper levels of an organizational culture, with a high-trust climate as a more observable manifestation on the surface of that culture (Schein, 1990). Trust refers to a 
willingness to be vulnerable to the actions of other organizational members based on positive expectations of their intentions (Mayer et al., 1995). When the organizational culture is grounded in the belief that organizational members tend toward psychological growth and psychological and social integration, as implied in the autonomous and collective orientations, trust is likely to prevail among peers and between super- and subordinates. Therefore, a high-trust orientation is one of the major dimensions of a stewardship culture (Schoorman et al., 2007).

A high-trust orientation can be linked to the idea dissemination phase, which is the second phase of the innovation process. Dissemination implies that organizational members speak up with their innovation ideas. Yet, promoting one's ideas is not without risks. Other organizational members may, for instance, judge one's idea as being not particularly novel or useful. Suggestions for innovations also challenge the status quo, thereby raising levels of uncertainty. Those individuals directly affected by the proposed change may then vigorously resist the innovation idea. Therefore, without mutual trust organizational members are less willing to take the risk of speaking up due to fears that others will be quick to criticize, ridicule or discipline them (McLean, 2005). For idea dissemination to take place there must be a hightrust climate characterized by openness and free communications (Baer \& Frese, 2003).

Collective Orientation and Idea Realization. A collective orientation entails that organizational members are driven by, and experience social demands for, concern for the wellbeing of the collective organization, as opposed to their own self-interest. This idea is central to stewardship theory which portrays a steward as someone "whose behavior is ordered such that pro-organizational, collectivistic behaviors have higher utility than individualistic, self-serving behaviors” (Davis et al., 1997: 24). A stewardship culture's strong collective orientation thus implies that the contentment of organizational members is positively associated with the longterm success of the organization.

The collective orientation of a stewardship culture can be related to the last phase of the innovation process being the actual realization of the proposed innovation idea. This phase comprises all events related to putting an innovation into effective use such as resource attainment, technical development, and utilization. Idea realization is primarily an interindividual collaborative process requiring the cooperation of numerous members across hierarchical levels (e.g., workers, managers, owners) and departments (Anderson \& King, 1993). A stewardship culture's collective orientation, with organizational members being committed to the long-term well-being of the company (Davis et al., 1997), will facilitate this idea realization phase. Based on their organizational commitment, collectivists will be inclined to invest their time, energy, and money in the innovation suggestions of others, to be helpful and collaborative, to engage in proactive behaviors in the face of problems, and to demonstrate perseverance when confronted with implementation difficulties.

\section{Family-Based Sources of Stewardship}

In this section, we develop arguments for why early generation (i.e., parental and sibling) family firms might be characterized by a stronger innovation-supportive stewardship culture than nonfamily firms, and why late generation (i.e., cousin) family firms may well have lost these stewardship advantages. Based on insights drawn from self-determination theory and the family business literature, we will argue that the social conditions in early generation family firms satisfy their organizational members' psychological need for relatedness which, in turn, enhances autonomy, trust, and collectivism. Subsequently, we explain how the dynamics in late generation 
family firms bring down relatedness feelings, making the prevalence of an innovation-supportive stewardship culture no more likely among these firms than in a nonfamily firm setting.

Relatedness and Community Building. Relatedness reflects a fundamental psychological need capturing people's desire for belongingness, security, and connectedness in social groups i.e., the desire to care and to be cared for (Deci \& Ryan, 2000). Whereas nonfamily firms tend to focus primarily on impersonal financial objectives, most family firms (especially the early generational forms, cf. infra) also consider various nonfinancial aspects that meet the family members' affective needs. These affective family considerations come in a variety of forms, including concerns for security, comfort, and belonging (Gomez-Mejia et al., 2007). Put differently, in addition to providing economic wealth for the family, family firms are typically also used as a vehicle to nurture family members' feelings of relatedness. These relatedness feelings are not limited to members of the family alone. Based on the owning-families' unusual concern for the firm's long-term well-being, investing generously in the building of a cohesive community of loyal employees is highly characteristic for family firms (Miller et al., 2008). These so-called community building activities (e.g., inclusive training programs, flexible work arrangements) give employees a sense of being cared for by the family, thereby extending relatedness feelings to nonfamily organizational members. Community building and relatedness feelings are less common among nonfamily firms which tend to emphasize economic rationales and transactional as opposed to relational interactions (Miller et al., 2008).

According to self-determination theory, satisfaction of the organizational members' need for relatedness will enhance their intrinsic and well-internalized extrinsic motivation, which are the two autonomous motivational forms (Deci \& Ryan, 2000). Intrinsic motivation reflects people's natural tendency toward engagement in interesting activities, with this engagement promoting psychological growth. Self-determination theorists assert that, in order to be sustained, intrinsic motivation requires a social setting in which people feel securely attached to others. In the words of Deci and Ryan (2000: 235), "a secure relational base appears to provide a needed backdrop - a distal support - for intrinsic motivation, a sense of security that makes the expression of this innate growth tendency more likely and more robust”. Hence, the feelings of relatedness characteristic for family firms can be expected to stimulate intrinsic motivation among organizational members.

Self-determination theory also maintains that relatedness feelings enhance organizational members' well-internalized extrinsic motivation to serve the collective (Ryan \& Deci, 2000). Organizational members experience socially sanctioned norms soliciting them to be actively engaged and committed to the well-being of the firm (Gagné \& Deci, 2005). When organizational members internalize these extrinsic social demands by recognizing their underlying value and transforming them into personally endorsed goals, they are said to have a well-internalized extrinsic motivation to serve the collective organization. This internalization process is a natural process that people engage in to achieve social and psychological integration, but to be sustained it requires nutriments from the social environment in the form of relatedness feelings (Deci \& Ryan, 2000). That is, the main reason why people internalize extrinsic social demands is because these demands are valued by relevant others to whom they feel attached.

We thus contend that family involvement in a firm promotes feelings of relatedness among organizational members which, in turn, foster intrinsic motivation and well-internalized extrinsic motivation to serve the collective organization. It should be noted that while intrinsic motivation refers to the autonomous orientation of a stewardship culture, well-internalized extrinsic motivation to serve the collective refers to both autonomy (sense of volition) and 
collectivism (behaviors aimed at the well-being of the collective organization). As discussed in the previous section, the autonomous and collective orientations both represent deeper levels of a stewardship culture with a high-trust climate being a manifestation of these two underlying cultural orientations on the surface of that culture. It is, therefore, not surprising that family firms are often depicted as high-trust organizations (e.g., Tagiuri \& Davis, 1996) with this trust grounded in secure and caring relationships. In brief, we propose that family firms have advantages in developing the cultural dimensions of autonomy (facilitating idea generation), trust (facilitating idea dissemination) and collectivism (facilitating idea realization). However, in line with the family firm heterogeneity argument (Chrisman et al., 2006), we do not expect this innovation-supportive stewardship culture to be equally strong across family firm types. Therefore, in what follows, we go beyond the simple family versus nonfamily dichotomy and consider different generational forms of family firms.

Generational Dynamics. In early generation (i.e., parental and sibling) family firms, most relatives share a history of intense social bonding within the same nuclear family unit and have strong attachments to the business (Gersick et al., 1997). So these early generation family firms are expected to care deeply about the involved relatives' affective needs and to invest generously in the building of a cohesive community of loyal employees so as to support the firm's long-term well-being - thereby, as discussed above, fostering the three dimensions of a stewardship culture. Late generation (i.e., cousin) family firms, however, differ in important ways from their predecessors. Relationships between cousins are often no stronger than those among nonfamily members, and members of the extended owning-family generally pursue more rationalistic and short-term oriented objectives (Lubatkin et al., 2005; Schulze et al., 2003). Hence, we propose that differences in the prevalence of an innovation-supportive stewardship culture exist between nonfamily firms and early generation family firms, while there may be no such difference when considering late generation family firms.

Hypotheses. The hypotheses below formally summarize our main expectations. While these hypotheses do not capture all facets of the developed theoretical model, their confirmation would lend initial credibility to it. In other words, these hypotheses form the basis for a first exploratory empirical test. We stress that future empirical work is needed to determine the validity of the proposed model in a more extensive and fine-grained manner.

H1: As a result of a stronger stewardship culture, parental and sibling family firms are more innovative than nonfamily firms.

H2: As a result of a stronger stewardship culture, parental and sibling family firms are more innovative than cousin family firms.

H3: As a result of a comparable stewardship culture, parental and sibling family firms are equally innovative.

H4: As a result of a comparable stewardship culture, nonfamily firms and cousin family firms are equally innovative.

\section{METHOD AND RESULTS}

The hypotheses were tested using survey data from 172 privately-held manufacturing SMEs located in the Dutch-speaking part of the Benelux (The Netherlands and the Flemish region in Belgium). Our independent variable firm type is derived from a set of survey questions on family ownership, family leadership, and respondent perceptions. Our dependent variable 
technological innovation is based on a scale by Zahra et al. (2000) which produced two factors: product innovation (five items, Cronbach's alpha=0.89) and process innovation (three items, Cronbach's alpha=0.81). We controlled for firm age, firm size, industry growth, industry competitiveness, and country. Our hypotheses were tested using multiple regression analyses.

The empirical tests provided exploratory evidence for the proposed model. For both types of technological innovation (i.e., product and process innovations) we found statistical support in our data for hypotheses 2, 3 and 4. As for hypothesis 1, parental and sibling family firms were found to be significantly more innovative than nonfamily firms only when process innovation was used as a dependent variable.

\section{DISCUSSION}

Few prior studies examined the entrepreneurial capabilities of family firms, and perspectives vary greatly among scholars (Miller et al., 2008; Short et al., 2009). This article presented a theoretical model outlining how and when family involvement might affect the intraorganizational innovation process. By extracting themes from stewardship theory (Davis et al., 1997) we developed the notion of an innovation-supportive stewardship culture. We then argued that the strong relatedness feelings prevailing in early generation family firms foster this type of organizational culture, leading to innovation advantages for these firms when compared with late generation and nonfamily firms.

Overall, the empirical findings lend credibility to our theory. Yet, our results also indicate that there is value in distinguishing between different types of technological innovation. Process innovations are directed at improving the efficiency and reliability of production technologies, generally leading to improved service for existing clients at a lower price (Harrison et al., 2008). Product innovations, on the other hand, are directed at creating new demand and involve more substantial risks given the uncertain acceptance by the market (Hargadon \& Douglas, 2001). Hence, our finding that the hypothesized effects are most significant with regard to process innovations is not surprising as family firms are often said to prefer avoiding risks and to be highly committed to the building of long-lasting relationships with their clients (Miller et al., 2008). In practice, of course, product innovations often accompany process innovations and we do find that early generation family firms have advantages with regard to product innovations as well, especially when compared with late generation family firms.

Future research may explore to what extent our model holds true across time, space, and institutional settings. For example, our arguments might not hold for large publicly-traded family firms where the family's connection to the business is generally lower than in smaller privatelyheld family firms. There are also various geo-cultural variations in the attributes of families that may affect the validity of the developed theory. Moreover, our data only allowed us to test a number of exploratory hypotheses derived from the model, with their confirmation lending initial credibility to the developed theory. Hence, future work with measures of the various stewardship dimensions (autonomy, high-trust, and collectivism) and phases of the innovation process (idea generation, idea dissemination, and idea realization) will be needed to further determine the validity of our theoretical argumentation. It is, therefore, our hope that the model presented in this study will serve as a theoretical backdrop for upcoming empirical work on intraorganizational determinants of innovation.

\section{REFERENCES AVAILABLE FROM THE AUTHORS}

